\title{
Lope y Calderón: una lectura filosófica
}

\section{Lope and Calderon: a philosophical reading}

\author{
VIOLETA VARELA ÁLVAREZ \\ Universidad de Coimbra
}

Recibido: 14-04-2009 Aprobado definitivamente: 25-01-2010

\section{RESUMEN}

Se trata, en esta investigación, de hacer una aproximación moral, política y filosófica al teatro español del Siglo de Oro a través de dos de sus más paradigmáticos creadores: Lope de Vega y Calderón de la Barca. Me apoyo para ello en una definición política de lo trágico que se encuentra arraigada en la tradición greco-latina del género. Se investigará si en las obras analizadas de Lope y Calderón lo trágico aún se encuentra delimitado por lo político, deduciéndose, como se verá, que en Lope tal relación ha desaparecido, mientras que en Calderón se mantiene, pero eliminándose el enfoque dialéctico debido a la afirmación de los códigos del Honor.

PALABRAS CLAVE

TRAGEDIA ESPAÑOLA, TRADICIÓN CLÁSICA, ESTÉTICA, TEORÍA DE LA LITERATURA, LITERATURA COMPARADA

ABSTRACT

This paper is a moral, philosophical and political approach to the theatre of Spanish Golden Age based on a philosophical and political conception of the tragic literature. We focus our attention on two classic authors: Lope de Vega and Calderon de la Barca. A comparative approach between Greek tragedy and the Spanish plays will help us define if the tragic bias is limited by a political aspect in Lope and Calderon. Finally, we intend to deduce that politics have disappeared in Lope's plays and still exist in Calderon, although not in a dialectical way due to the code of Honour.

\section{KEYWORDS \\ SPANISH TRAGEDY, CLASSICAL TRADITION, AESTHETICS, LITERARY THEORY, COMPARATIVE LITERATURE}




\section{LA CONCEPTUALIZACIÓN DEL GÉNERO TRÁGICO}

Se trata de ANALIZAR dos obras de la literatura española que han sido incluidas, tanto por la crítica como por sus propios autores -en el caso de Lope-, dentro del género de lo trágico. Acogiéndome a la definición de muchos estudiosos que apunta a que la verdadera tragedia representaría siempre un conflicto de naturaleza socio-política ${ }^{1}$, pretendo examinar si pueden considerarse trágicas las obras analizadas de Lope y Calderón. A la vez, será importante contemplar el tratamiento que se ofrece de los motivos políticos, en caso de haberlos: ¿consideración dialéctica de naturaleza conflictiva, o visión armónica? Tal cuestípon se volverá fundamental a la hora de juzgar la concepción que ambos autores representaban de los códigos del honor y de la sociedad estamental en la que se desenvolvían. Por último, se estudiará si lo trágico queda reducido en sus obras a la simple exposición de hechos sangrientos, truculentos y violentos, despojados de la trascendencia moral y socio-política que lo trágico lleva consigo e, incluso, considerados cómicamente.

Me enfrentaré, por lo tanto, en este trabajo, con otras concepciones de lo trágico esgrimidas por la crítica, y que responderían, por ejemplo, a las siguientes caracterizaciones:

1. Quienes sostienen que la tragedia del XVII se caracterizaría, fundamentalmente, por referencia a la comedia: coincidencia en los esquemas dramáticos e inversión en el desarrollo de la fábula (Ynduráin, 1987: 144).

2. Quienes sostienen que la tragedia española del XVII podría caracterizarse fundamentalmente por los siguientes rasgos: 1) Historicidad o argumento no ficticio, 2) desenlace con muerte o funesto, 3) gravedad, 4) personajes elevados (Morby, 1943).

Sencillamente, deseo aportar otro punto de vista que, siendo menos aislacionista, sitúe a Lope y Calderón en la historia del teatro trágico desde sus orígenes griegos, tratando así cuestiones de literatura comparada y tradición clásica. Mientras Calderón parece apostar por una amalgama entre tragedia y comedia que empobrece lo trágico hasta hacerlo desaparecer, a pesar de mantener los motivos políticos, Lope parece centrar el conflicto de la obra en realidades pasionales, elaborando así un drama ejemplarizante del que los elementos políticos han desaparecido como motor de la acción. Veámoslo con mayor detenimiento.

1 Muchos son los autores que sostienen una definición política del género trágico. Citaré, a modo de ejemplo, los siguientes: Jaeger (1933/1954: 248), Murray (1940/1954: 29), Luis Gil (1988), Carlos García Gual (1988: 182-183), Adrados (1992: 4, 5), Trapp (1996: 82), Pelling (1997: 224), Parker (1997: 146), Vidal-Naquet (2001/2004). Remito, para una justificación detallada, al capítulo primero de Varela Álvarez (2008). 


\section{Sobre El CARÁCTER TRÁGICO DE EL CASTIGO SIN VENGANZA}

Lope conceptualizó sin reservas El castigo sin venganza como tragedia, ${ }^{2}$ tanto en la dedicatoria, como en el prólogo, y en los versos finales de la obra. ${ }^{3}$ En el prólogo de El castigo sin venganza señala en qué sentido puede considerarse esta obra como una tragedia:

Señor lector, esta tragedia se hizo en la corte sólo un día, por causas que a vuesa merced le importan poco. [...] está escrita al estilo español, no por la antigüedad griega y severidad latina; huyendo de las sombras, nuncios y coros, porque el gusto puede mudar los preceptos, como el uso los trajes y el tiempo las costumbres (apud Ynduráin, 1987: 146).

El castigo sin venganza ofrece, en consecuencia, la visión ideal y trágica (desde el punto de vista del autor) de unos hechos en origen no ficticios. ${ }^{4}$ De la caracterización trágica que Lope impone a su obra podemos deducir que pretende para ella un cierto carácter pedagógico, ejemplarizante y moral. ¿Qué pretende transmitir Lope en esta obra? Para responder nos es sumamente útil lo dicho por el autor en las páginas 282-284 de su obra, La más prudente venganza, perteneciente a «Las novelas a Marcia Leonarda». El objetivo de la tragedia para Lope es claro: fabula hechos no ficticios modificados para ofrecer un relato ejemplarizante. Si hacemos caso a lo manifestado por Lope en su novela habría que concluir que ambas tragedias lopescas, ya en prosa, ya en verso, servirían a la deslegitimación de la venganza en los casos de honra, crítica amparada en la mentalidad católica, según la cual debe dejarse siempre abierta la vía del arrepentimiento y de la salvación del alma. La conclusión nos parece clara: el catolicismo impide la tragedia, la venganza la precipita. ${ }^{5}$ Esto es fundamental,

2 Mientras que el propio Lope consideró como una tragicomedia su obra El caballero de Olmedo, El castigo sin venganza fue concebida, insisto, por el propio autor como una tragedia, ¿a qué obedece tal diferencia? La diferencia podría residir en el origen no ficticio de lo representado en la tragedia, historia no ficticia que el autor no duda en modificar adaptándose al principio aristotélico que diferencia la historia de la tragedia según la universalidad de lo relatado: la historia cuenta lo particular mientras que la tragedia relata los hechos como deberían haber sido. «Da la impresión de que Lope fluctúa y, aunque vaya contra el arte -nuevo o viejo- de hacer tragedias, mezcla lo cómico y lo trágico sin mayores problemas. A mi entender, lo que distingue y sirve de rasgo diferencial entre tragedia y tragicomedia no es tanto el nivel de los personajes, ni el final, sino la historicidad del argumento. Que se trata de un hecho histórico, y sacado de fuentes escritas, es algo que Lope deja claro. Por el contrario, la Celestina no posee esa historicidad» (Ynduráin, 1987: 148).

3 Ni la dedicatoria ni el prólogo aparecen en la edición de Kossoff (1985).

4 Para un examen de las fuentes de El castigo sin venganza remitimos a lo manifestado por Kossoff en su edición de la obra (1985: 20 y ss.).

$5 \ll[\ldots]$ si el protagonista, ante la muerte, tiene que arrepentirse con humildad de todos los errores de su vivir humano, puede que sea un santo, pero no un héroe trágico». (MacCurdy, 
porque sitúa la concepción de lo trágico en Lope como aquello que sirve a la reafirmación, por vía negativa, de las doctrinas católicas sobre la culpa, el arrepentimiento y el perdón divino: la venganza es una injerencia de los hombres en las competencias del dios católico. ${ }^{6}$ ¿Estamos, pues, ante auténticos ejercicios trágicos o ante dramas católicos moralizantes y ejemplarizantes? Voy a apostar por la segunda opción. ${ }^{7}$ Se trata, insisto, de algo muy relacionado con la crítica de los códigos del honor que encontramos implícitamente ejercida en la obra de Lope, como examinaremos posteriormente. La reparación que la honra exigía se encuentra íntimamente unida a la noción de venganza.

Fundamental es, llegados a este punto, aclarar el tipo de fenómeno al que asistimos en la obra: ¿castigo o venganza? Defiendo que el hecho dramatizado por Lope obedece a una venganza privada que será presentada públicamente como un castigo. ${ }^{8}$

Una vez esclarecido lo que respecta a los fines de lo trágico, en una perspectiva subjetiva del propio autor, llega el momento de discutir el resto de características trágicas no esenciales en las que se ha centrado la crítica en relación con la obra de Lope (Ynduráin, 1987; Alvar, 1987): 1) El tema del incesto. 2) El tono elevado que pretende alejarse del anteriormente usado aplauso del vulgo. 3) Los personajes de Aurora y el Marqués como figuras análogas del coro clásico. 4) La intervención decisiva de los hados y del fatum que va precipitando el fatal desenlace, como el accidente del coche, recién comenzada la tragedia. 5) La ironía trágica presente, sobre todo, en el personaje del Duque. 6) Las reminiscencias clásicas.

Respecto a estas características trágicas he de decir que son unas características muy discutibles. Para empezar, el tema del incesto resulta en la obra de

1989: I, 180).

6 Se ha hecho ver cómo este tipo de tragedias, que buscarían la deslegitimación de la venganza, tendría relación con el reinado de Felipe IV y su afición por los escarceos amorosos, aunque más bien debería relacionarse tal fenómeno con la adaptación a los gustos cortesanos. El nuevo escenario de representación que constituyeron los teatros reales exigía que los escritores compitieran por obtener la categoría de autor de cámara (Ynduráin, 1987: 150).

7 Estamos totalmente de acuerdo con lo afirmado por MacCurdy (1989: I, 178), cuando recoge la incompatibilidad, afirmada por varios críticos, entre los valores católicos y la perspectiva trágica: «Entre los valores españoles es el catolicismo, según los más de los críticos, lo que más impide la tragedia, porque lo verdadero trágico es incompatible con el esencial optimismo de la fe cristiana».

8 Disentimos, en consecuencia, de lo manifestado por Ynduráin (1987: 151): «[...] parece como si hubiera una progresión que llevara de la venganza al castigo, pasando por discreciones, secretos y prudencias: lo uno sustituye a lo otro, con todo lo que implica. Lope, incluso, se complace en dirigir al lector u oyente hacia la venganza para, en el último momento, con uno de esos quiebros magistrales, frustrar esa expectativa para sustituirla por el castigo, resultado nuevo y diferente, inesperado en cualquier caso. 
Lope muy diluido por dos motivos: Casandra es la madrastra de Federico, a lo que se añade la condición de bastardo de éste. Es cierto que Federico es tratado como un hijo por el Duque y que su situación hereditaria y dinástica no ofrece dudas, pero no deja de ser un bastardo, siendo tal condición la que prevalezca al final de la obra. Hay incesto, de acuerdo, pero nada tiene que ver con el reflejado por Sófocles o Séneca en sus dramatizaciones del tema de Edipo. De hecho, en cuanto a las fuentes clásicas, creemos que la relación entre Federico y Casandra debe más al Hipólito de Eurípides, que conoció una elaboración en la Fedra de Séneca (si bien la obra de Séneca podría basarse en la tragedia homónima de Eurípides que, desgraciadamente, no conservamos), que a ninguna versión griega o latina del mito de Edipo. Es más, mucho más incestuosa resultaría la relación de Federico con Aurora, a la que sí le une la sangre y con la que se ha criado como un hermano (vv. 700-717). En cuanto a las figuras de Aurora y el marqués, aun admitiendo su analogía con la figura del coro, no deja de ser una semejanza formal y estructural puesta al servicio de intereses muy contrarios a los de la tragedia clásica, lo mismo cabe decir del uso de nombres como Casandra o de ciertas citas que pretenden evocar la guerra de Troya. Por lo que toca a la postulada ironía trágica, disiento totalmente de la consideración de los hechos del Duque como trágicamente irónicos, en el sentido en que podrían serlo los de un Edipo. Lo trágico de la ironía sofóclea reside en la falsa seguridad edípica y en el afán con que el personaje se va precipitando hacia su desgracia. En el caso de la obra de Lope no asistimos a falsas seguridades ni a un adentrarse en la desgracia por parte del Duque. Asistimos a un marido adúltero que tiene completamente abandonada a su esposa, una esposa por la que no siente ninguna preocupación ni cuidado. El matrimonio no está entre las preocupaciones del Duque hasta que vuelve convertido tras luchar al servicio de la Iglesia. El desinterés malamente puede aparecer parejo a la tragedia o a la ironía trágica. Las escenas de la obra de Lope que podrían adquirir un tinte de ironía (los versos 2295 y ss.), adquieren en realidad un aire de comicidad derivado del personaje del Duque, hombre lujurioso y desleal que vuelve de la guerra hablando de la virtud y del amor a una esposa que, cansada de esperar, lo ha ido a buscar en los brazos de su hijastro. El personaje de Edipo, que se mantiene constante hasta quebrarse al final de la tragedia, poco tiene que ver con el personaje del Duque. Lo trágico de Edipo es su preocupación por una ciudad hostigada por la peste y por una mancha criminal que no se ha limpiado, una mancha de la que él es culpable sin saberlo: la ironía reside en sus esfuerzos por amenazarse y darse caza a sí mismo. En la obra de Lope, el Duque nunca tiene en consideración a su esposa. Ni siquiera se ha esforzado en obtener una descendencia legítima, porque acepta como heredero a su hijo bastardo. Su esposa no ha tenido ningún contacto con él. No es que confíe en la fidelidad de su esposa, es que le importa bien poco (ver el recitativo de Casandra en los versos 998-1043). 
Sólo a su vuelta se verá llevado del deseo de reanudar su vida matrimonial, y es entonces cuando será advertido de la traición que está sufriendo, traición que ya sabía todo el mundo menos él, no por incapacidad racional, sino por absoluta despreocupación. Cierto es que en el mito de Edipo también asistimos a la ceguera del protagonista, pero se trata de una ceguera que en Edipo obedece también a la información errónea manejada por el protagonista. No hay una fuerza oculta que mantenga al Duque alejado de la verdad. No son los hados los que precipitan los acontecimientos en la tragedia de Lope. Casandra y Federico se hubieran conocido igualmente aunque el coche no se hubiera accidentado (tal hecho puede servir, a lo sumo, de acontecimiento precipitador). En cuanto al enamoramiento, no hay que perder de vista que Casandra tiene más relación con Federico que con su propio marido. De todos modos, y aunque no tengo espacio en esta comunicación para demostrarlo, deseo señalar que en ninguna tragedia griega asistimos a la mera afirmación del Destino en forma de simple cadena de hechos que conducen unos a otros de modo inevitable. En la tragedia, la afirmación del Destino, en caso de haberla, es siempre problemática y es presentada dialécticamente frente a la Libertad.

Considero, pues, que, a pesar de que el propio Lope designe su obra con el nombre de tragedia, muchos son los datos que nos deben hacer, por lo menos, cuestionar tal denominación. Sostengo que estamos ante un drama pasional, y no ante una tragedia. El amor entre Casandra y el Conde provocará las iras del Duque, marido y padre, respectivamente, de los interesados, que elaborará un plan para darles muerte a los dos, haciendo pasar por un crimen que obedece a motivaciones políticas y su correspondiente castigo (la soberanía de Federico, como hijo bastardo, peligraría ante el nacimiento de un hijo legítimo de Casandra y el Duque), lo que es, en realidad, la venganza de una traición conyugal, con el agravante de ser su propio hijo el protagonista. Lo que parece, pues, que subyace a la actuación del Duque es el dolor por la traición de su hijo y de la esposa, y por el derrumbamiento de la nueva vida que había decidido emprender a la vuelta de la batalla. Ni siquiera enfoca su venganza dentro de los códigos del honor, ya que nunca hace pública la traición amorosa y justifica con mentiras los asesinatos. Lope limita los motivos políticos a una mera apariencia y, a la vez, desplaza los motivos morales de su obra al no ajustar la actuación del Duque a los códigos del honor, cuyos mecanismos serán claramente expuestos en la obra de Calderón que analizaremos a continuación. El Duque podría haber justificado sus acciones apoyándose en la ofensa que había sufrido su honra. Al no hacerlo parece que el mensaje de Lope es claro: no considera las leyes del honor lo suficientemente sólidas como para justificar un crimen tan terrible, entroncando así con lo que al principio señalamos acerca de su concepción de la venganza. Se trata, moralmente, de un punto de vista sumamente crítico. 
El Duque estaba decidido a dedicarse al cuidado de su esposa y a cambiar su actitud en el matrimonio (vv. 2322-2327). Tras tomar esta resolución descubre (por carta anónima -v. 2484 y ss.- y al escuchar una conversación privada entre Federico y Casandra -v. 2707 y ss.-) que ella se ha enamorado de su hijo y que él le corresponde.

En la obra de Lope son las pasiones, y no los hados, las que conducen la trama: el amor que nace entre Federico y Casandra; el afán posesivo de Casandra, que hace desistir a Federico de intentar disimular los hechos casándose con Aurora (vv. 2714-2737); el despecho de Aurora, que hace que rechace a Federico, objeto verdadero de su amor. Todas estas actuaciones irán evidenciando a los ojos del Duque lo que le había sido comunicado por carta.

No hay ni rastro de la dialéctica moral familiar-poder político en la obra de Lope (se trata del único conflicto de naturaleza política que, por el argumento, podría ser susceptible de tratarse en esta obra). Nada nos dice la obra de los conflictos que trae consigo el deber político, es más, los motivos políticos se encuentran totalmente desplazados por las frivolidades amorosas y pasionales. ${ }^{9}$ Federico no sólo se olvidará de sus inquietudes al conocer a Casandra, sino que llegará a tener como único eje de su vida el amor que siente por ella. De hecho, tales inquietudes existieron antes de enamorarse. Así interpreto los siguientes versos:

Federico- [...] de mí mismo quisiera retirarme, / que me cansa el hablarme / del casamiento de mi padre, cuando / pensé heredarle, que si voy mostrando / a nuestra gente gusto, como es justo, / el alma llena de mortal disgusto, / camino a Mantua, de sentido ajeno, / que voy por mí veneno / en ir por mi madrastra, aunque es forzoso. [...] Mas ¿qué me importa a mí que se sosiegue / mi padre y que se niegue a los vicios pasados, / si han de heredar sus hijos sus estados, / y yo, escudero vil, traer en brazos / Algún león que me ha de hacer pedazos? (vv. 247-312).

9 De hecho, Lope habría sido señalado en más de una ocasión como el responsable de la extinción del género trágico en España. «Al contrario, Agustín Montiano, en el Discurso sobre las tragedias españolas, no vacila en reclamar para los españoles una natural inclinación a la tragedia: «La causa de esta propensión a los asuntos Trágicos, serios y magníficos, creo descubrirla en el carácter distintivo de los Españoles, ... es naturalísimo, que [España] prefiera la circunspección Trágica; la lástima que excita; la verosimilitud que observa; el provecho que produce y la racionalidad que guerda; a las frusilerías inoportunas; a la insensibilidad del ánimo; a los acaecimientos impossibles; a una ocupación estéril, y a un absoluto trastorno del discurso: y esto, no sólo quando se alcanza a discernir lo mejor, sino aun quando está escondida la propensión a lo bueno». Huelga decir que para Montiano, clasicista empedernido, Lope de Vega fue el responsable de haber desvirtuado dicha inclinación española a la tragedia» (MacCurdy, 1989: I, 176). De la misma opinión habría sido también Martínez de la Rosa (apud MacCurdy, 1989: I, 177). 
Las inquietudes desaparecerán al conocer a Casandra, de la que se enamora inmediatamente, pues la atracción es recíproca (véase el diálogo entre Federico y Batín, v. 623-651 y el diálogo entre Casandra y Lucrecia, v. 582-606). Un amor que, en mi opinión, no se debe a la fuerza de ningún hado (Ynduráin, 1987: 156), sino a la atracción física que sienten mutuamente, y a las pocas ganas que tiene Casandra de unirse a un hombre licencioso como el Duque (los hechos posteriores demostrarán que los temores de Casandra ante su casamiento eran ciertos). El Duque no se preocupa en ningún momento por el hecho de que su única descendencia sea ilegítima, y nunca duda de que Federico es su heredero de pleno derecho, hasta el punto de sentirse culpable (vv. 658-666) por su unión con Casandra («y fue casarme traición», v. 667).

Aurora finge que se casa con Federico para que éste se sosiegue al ver asegurado su poder, cuando, en realidad, lo que desea es casarse con el hombre al que ha amado desde su infancia (vv. 730-733). Las motivaciones políticas sólo existen en el terreno de las apariencias, son absolutamente falsas y no mueven en realidad a ninguno de los personajes.

En El castigo sin venganza el único conflicto político que encontramos es falso, es urdido ad hoc por los protagonistas para disimular los verdaderos motivos de la acción: Aurora y el Duque fingen problemas sucesorios y el Duque fabulará de cara al público un conflicto entre sus deberes morales como padre y sus deberes políticos como Duque, cuyo legítimo heredero en camino (también fingido) es asesinado (otra mentira), con la necesaria muerte de la madre, por un hijo bastardo que no desea ser expulsado de la línea sucesoria. Se finge, públicamente, un conflicto que atañe a la legitimidad, el derecho, la sucesión y el poder, para encubrir, privadamente, una trama de celos y pasiones furtivas (vv. 2738-2759, 2981-2987). Veamos cómo el Duque lo refiere en los versos que citamos a continuación:

Cielos, / hoy se ha de ver en mi casa / no más de vuestro castigo. / Alzad la divina vara. / No es venganza de mi agravio; / que yo no quiero tomarla / en vuestra ofensa, y de un hijo / ya fuera bárbara hazaña. / Éste ha de ser un castigo / vuestro no más, porque valga / para que perdone el cielo / el rigor por la templanza. Seré padre y no marido, / dando la justicia santa / a un pecado sin vergüenza / un castigo sin venganza. / Esto disponen las leyes / del honor, y que no haya / publicidad en mi afrenta/ con que se doble mi infamia. / Quien en público castiga / dos veces su honor infama, / pues después que le ha perdido, / por el mundo le dilata. (vv. 2834 - 2857).

En la obra de Lope, el núcleo de lo trágico ha desaparecido completamente dando lugar, eso sí, a un magnífico e inteligentísimo drama que juega magistralmente con la política como pretexto. Lope fabula un brillantísimo juego entre apariencia y realidad, entre falsedad y verdad, entre lo trágico y lo político como pretexto frente a lo dramático y pasional como texto. En consecuencia, 
habría que afirmar que la política, en la obra analizada de Lope, es irrelevante, desapareciendo así los motivos trágicos que venían animando el género desde la antigüedad clásica y propiciando el surgimiento de un enfoque propio del género dramático en el que lo fundamental son las pasiones y las acciones que desencadenan al afectar la psique de un determinado individuo. Ahora bien, lo que sí existe en la obra de Lope, a mi juicio, es una profunda crítica de los códigos del honor, ya que el dramaturgo se niega a usarlos como justificación de las acciones criminales. Esta crítica de los resortes que sustentan la honra, implícita en la obra de Lope a través de su elocuente ausencia, supone una postura moral del autor ciertamente reseñable y novedosa. Téngase en cuenta, insistimos, que la reparación del honor podía perfectamente justificar las acciones del Duque, no hacía falta recurrir a mentiras, pero éste, al optar por una fingida explicación política frente a la real explicación moral, parece situarnos ante un Lope que consideraba la política y sus motivos como algo mucho más legítimo que la honra y sus mecanismos. Si en Lope existiesen motivos políticos más allá de la simple apariencia, todo parece apuntar a que quedarían situados por encima de las leyes del honor. Muy distinto será el caso de Calderón, como veremos.

\section{Sobre El CARÁCter tRÁGICO DE EL MÉDICO DE SU HONRA DE CALDERÓN de LA Barca}

Respecto a la obra de Calderón, me centraré en la discusión acerca de la posible naturaleza conflictiva de los motivos reflejados en la obra y el examen del tratamiento que ofrece de la violencia.

La fábula nos relata un crimen pasional: el asesinato de una mujer por orden del marido y por motivos de celos y de honra. El hombre instiga al asesinato de su mujer creyendo, falsamente, que ésta ha cometido adulterio con el infante don Enrique. Tal crimen aparece además justificado en la obra de Calderón, que otorga al homicida un final feliz y un nuevo matrimonio con Leonor (v. 2940 y ss.).

El tema de la justificación de crímenes horribles no es nuevo en el amplio campo de los sucesos trágicos. En la tragedia griega, lo que dota de dignidad trágica a tales sucesos y lo que les confiere un carácter, valga la redundancia, trágico es su inserción en el enfrentamiento existente entre el ámbito de la moral familiar y el ámbito de la moral estatal o política. La visión trágica nunca ha dejado de mostrar el dolor de quienes debían perder. Un crimen como el que presenta Calderón es, por principio, absolutamente incompatible con la experiencia trágica, ya que en el clásico español la muerte de la mujer no significa nada. ${ }^{10}$ Su muerte no importa a nadie, a excepción, como veremos más adelante,

10 No creemos que el final de la obra pueda ser interpretado como irónico (O'Connor, 1982: 788-789). El final de la obra es un final feliz e incluso cómico. La actitud de Leonor, del 
del gracioso Coquín. Incluso con su cadáver delante, Calderón decide resolver cómicamente la obra. No cabe menor falta de respeto por una vida humana, desprecio que casa muy mal con una perspectiva trágica. ${ }^{11}$ La muerte de la esposa es despojada de cualquier trascendencia en la obra de Calderón. Con su cadáver sangrientamente presente, se prepararán nuevas nupcias para el homicida, bodas auspiciadas por el rey, que, conocedor de todos los hechos, no considera que la muerte de la mujer merezca ningún tipo de castigo. La obra nos ofrece un final feliz y la razón calderoniana triunfa en las palabras del rey. La obra supone de principio a fin la afirmación acrítica y simplista de los códigos del honor, ${ }^{12}$ unos códigos que el Rey pone por encima de todo: ya sea por encima de distinciones estamentales (Enrique no se salva a pesar de su condición de noble), o de pruebas y realidades (Enrique y Mencía jamás materializaron su relación). Las leyes del honor no obedecen ni a estamentos ni a realidades y las muertes derivadas de su aplicación no se cuestionan, ni se censuran, ni se juzgan. Son esos mismos códigos los que definen el honor como una categoría que se mueve siempre en el plano de la apariencia: no importa tanto tener la honra intacta como aparentarlo. Si la apariencia del honor se desvanece por actuaciones que, en realidad, no suponen ningún deshonor (como lo pueda ser una relación ficticia), entonces, igualmente, la honra debe ser reparada de forma ostentosa y pública, como en la obra de Calderón. Es cierto que Mencía y Enrique no deshonraron a Gutierre, pero no es menos cierto que causaron una apariencia deshonrosa que el protagonista repara con la muerte de su inocente esposa. La apariencia que sostiene la honra de Gutierre se restablece por medio de un vistoso crimen que se exhibe de manera jactanciosa ante el Rey y los demás espectadores. En cuanto a la relación que media entre las leyes del honor y la configuración estamental, debe reseñarse el hecho de que en Calderón los códigos del honor anulan toda diferencia social o estamental, lo cual es un dato fundamental, ya que en otros autores, como Rojas Zorrilla en su supuesta obra Del rey abajo ninguno, el honor sólo puede repararse si quienes lo han dañado

rey y de Gutierre es de absoluta complacencia ante las nuevas nupcias, y la joven, que confía en su virtud, nada parece temer por su futuro casamiento con un hombre capaz de tan brutales acciones.

11 La vida, en la experiencia trágica, es un valor despreciable frente a otros, pero un valor al fin y al cabo. Si la vida no fuera absolutamente fundamental e importante, si no fuera lo único que posee el hombre, su sacrificio no sería nunca trágico.

12 Discrepamos, pues, del juicio de O'Connor respecto al tratamiento del honor en la obra: «Por decirlo así, demuestra [Calderón] cómo se divorció el honor de la virtud, su fuente tradicional, a medida que describe qué recursos utilizará el hombre al proteger su lugar en la jerarquía social. [...] En El médico de su honra a Calderón le interesan más los problemas humanos que subrayan los apuros obvios provocados por una consideración irrazonable del honor» (1982: 785). 
pertenecen a la misma, o inferior, escala social que el ofendido, mientras que si la deshonra la causa alguien de un estamento superior, los códigos del honor no tienen ninguna relevancia y el ofendido no puede defenderse ni reparar su honra. Calderón muestra así un idealismo socio-político en su obra que en autores como Rojas desaparece ante las realidades de poder que efectivamente funcionaban en la España aurisecular.

En la obra de Calderón, el rey representa la razón. Su juicio acerca de los hechos es el que se impone al final del drama, un juicio exculpatorio y acrítico que sanciona, no castigándola, y premia, con un nuevo casamiento, lo correcto y lo moral de la actuación de Gutierre enmarcada en el código del honor, según el cual las ofensas aparentes justifican una reparación tanto como una ofensa real.

Lo que podría haber sido un hecho trágico: la muerte brutal de una mujer inocente por las sospechas de su marido, se reduce a una anécdota sin importancia, incluso es la vía que permitirá la solución de los problemas de honra que sufre Leonor.

Podría aducirse, como ya he indicado al comienzo de este apartado, que en la obra de Calderón asistimos efectivamente a dos enfoques dialécticos: el sexual y el estamental (O’Connor, 1982). En este artículo voy a defender que en absoluto puede hablarse de la presencia de tales dialécticas en la obra de Calderón. Veámoslo con más detenimiento.

1-La dialéctica estamental. ${ }^{13}$ Sostengo que la obra de Calderón tiene como uno de sus principales objetivos la negación de tales conflictos respecto a la Idea del Honor aurisecular. Lo importante no es el estamento al que pertenezca el individuo, sino la honra que caracteriza su vida. Por eso Gutierre queda por encima del infante Enrique, porque Gutierre ha cumplido con las leyes del honor al mandar asesinar cruelmente a su esposa, mientras que Enrique ha intentado violar esas mismas leyes, aunque sin éxito, teniendo relaciones con una mujer casada. No estamos, pues, ante un planteamiento dialéctico, sino ante una afirmación acrítica e idealista, insistimos, del honor y sus procedimientos. Veamos las palabras del rey afirmando el honor sobre cualquier distinción de tipo socio-político:

13 Dice O'Connor (1982: 784): El Príncipe don Enrique se comporta arrojadamente, sin preocuparse de los problemas que provoca para Mencía. Al abusar de su posición y de sus poderes reales, se niega a considerar la situación que ella describe [...] Doña Mencía de Acuña será la víctima inocente de este Príncipe ególatra, aunque ya lo fuera con anterioridad al ser forzada por su padre a casarse con don gutierre Alfonso Solís». Es cierto, pero este hecho no justifica el encontrar en la obra ningún tipo de crítica social. La actitud de Enrique sirve a Calderón para, a través de la figura del Rey, demostrar y enunciar textualmente una doctrina en la que el honor es lo único fundamental. 
Rey- Vos, Enrique no sabéis / que más de un acero tiñe / el agravio en sangre real. / Don Enrique- Pues, ¿por quién, señor, lo dice / Vuestra Majestad? Rey- Por vos / lo digo, por vos, Enrique; / el honor es reservado / lugar, donde el alma asiste; / yo no soy Rey de las almas: / harto en esto solo os dije. / Don Enrique- No os entiendo Rey- Si a la enmienda / vuestro amor no se apercibe, / dejando vanos intentos / de bellezas imposibles, / donde el alma de un vasallo / con ley soberana vive, / podrá ser de mi justicia / aun mi sangre no se libre. (vv. 2189 y ss.).

2-La dialéctica sexual. ${ }^{14}$ En la obra de Calderón no hay ninguna crítica al sometimiento de la mujer, todo lo contrario. No sólo encontramos en la obra referencias a la esclavitud que supone el rol de esposa (como en los versos 1240-1241, referencias que no encuentran ninguna afirmación opuesta que las contrarreste), sino que, además, lo que es perverso para una mujer, Mencía, acabará siendo la solución para otra, Leonor. La muerte de Mencía supone la salvación de Leonor, que por fin obtendrá un matrimonio legítimo de quien se lo había prometido. ${ }^{15}$ Veamos cómo reciben los implicados el mandato real que les obliga a casarse:

Rey- Dásela, pues, a Leonor, / que yo sé que su alabanza / la merece. Don Gutierre- Sí la doy. / Mas mira, que va bañada / en sangre, Leonor. Doña Leonor- No importa; / que no me admira ni espanta. / Don Gutierre- Mira que médico he sido / de mi honra: no está olvidada / la ciencia. Doña Leonor- Cura con ella / mi vida, en estando mala. / Don Gutierre- Pues con esa condición / te la doy [...]. (vv. 2940-2951).

¿Dónde está, en estas palabras, la solidaridad sexual que señalan algunos críticos? Leonor lo dice textualmente: ni le admira ni le espanta el crimen, ${ }^{16}$ al

14 «En esta ponencia me propongo ensanchar el enfoque tradicional del drama para incluir las relaciones básicamente problemáticas entre el hombre y la mujer» (O'Connor, 1982: 783).

15 Recordemos que Leonor rechaza a don Arias porque cree que su unión podría servir de confirmación a antiguas sospechas (vv. 1755-1784).

16 Otra vez hemos de mostrar nuestro profundo desacuerdo con la interpretación de O'Connor (1982: 786-787): «Al acabar la obra doña Leonor con don Gutierre subraya la victimización de las mujeres por parte de los hombres. Acabamos de presenciar el sacrificio de doña Mencía en arras del honor- y con manos ya bañadas en sangre de ella, el sumo sacerdote del honor extiende el vínculo matrimonial a doña Leonor, víctima anterior y, en esta escena horripilante, probable candidato a la victimización. [...] En el asesinato de la inocente Mencía y en la victimización de la ingenua Leonor, Calderón revela las costumbres aceptables de su sociedad, una sociedad establecida sobre un patrón falso y destructivo, el que necesita la subordinación de todas las mujeres al poder y privilegio masculinos. Al llevar a cabo ineluctablemente esta deuda del honor, Calderón revela tácitamente las suposiciones horribles de su sociedad dominada y orientada por los hombres». Para empezar hemos de decir que nada vemos de ingenuo en el comportamiento y carácter de Leonor: es vengativa (desea que el mal que le ha causado Gutierre revierta en él, vv. 1007-1020); es astuta (sabe que el matrimonio con don Arias no le devolverá 
igual que a todos los personajes de la obra salvo, es curioso, al gracioso Coquín, único personaje que califica de viles los celos de Gutierre y que siente horror ante la muerte de Mencía. Este personaje, el del gracioso, es el único que parece tener cierta conciencia de lo abyecto y cruel del crimen, un personaje cuyas opiniones quedan desacreditadas en la obra por su carácter de «gracioso» y de «cobarde» (v. 1253 y ss., obsérvese el contraste que plantea Calderón entre Gutierre y Coquín en este diálogo en concreto. Don Gutierre, futuro asesino de su esposa a través de un forzado Ludovico, representa la honradez de quien, pudiendo huir de la justicia, no lo hace). ¿Cómo va a entender un gracioso cobarde las cuestiones del honor? Veamos el parlamento de Coquín en los versos 2728 y ss.

Ésta es una honrada acción / de hombre bien nacido, en fin; / que aunque hombre me consideras / de burlas, con loco humor, / llegando a veras, señor, / soy hombre de muchas veras. / Oye lo que he de decir, / pues de veras vengo a hablar, / que quiero hacerte llorar, / ya que no puedo reír. / Gutierre, mal informado / por aparentes recelos, / llegó a tener viles celos / de su honor; y hoy, obligado / a tal sospecha, que halló / escribiendo (jerror cruel!) / para el Infante un papel / a su esposa, que intentó / con él que no se ausentase, / porque ella causa no fuese / de que en Sevilla se viese / la novedad que causase / pensar que ella le ausentaba... / con esta inocencia pues / (que a mí me consta), con pies / cobardes, adonde estara / llegó, y el papel tomó, / y, sus celos declarados, / despidiendo a los criados, / todas las puertas cerró, / solo se quedó con ella. / Yo, enternecido de ver / una infelice mujer, / perseguida de su estrella, / vengo, señor, a avisarte / que tu brazo altivo y fuerte / hoy la libre de la muerte.

Podría decirse que es el gracioso el personaje sobre el que recae la dura labor de decir la verdad. Podría sostenerse que Calderón pensaba igual que el gracioso, pero la verdad es que nunca sabremos lo que pensaba Calderón, lo que se puede demostrar es que el final de la obra apunta a que el crimen no se contempla como algo negativo en esta pieza teatral, y lo que se puede demostrar también es que afianzar la pertinencia de los códigos del honor, como hace

su posición social anterior); es cruel (bien le dice a Gutierre, con el cadáver de Mencía presente, que si ella actúa mal, él le dé la misma medicina: su juicio sobre el asesinato de Mencía es claramente aprobatorio, Mencía se lo ganó por introducir dudas en la honra de su marido, ella sí es virtuosa, su deshonra se debió a un error y a un malentendido, por eso se entrega a Gutierre con la confianza de quien se cree mejor); y no siente ninguna lástima por Mencía (más claro no se puede decir, el crimen no le causa ni admiración ni espanto, como tampoco las ensangrentadas manos de su futuro esposo). Calderón muestra un acto horrible, es cierto, cosa muy distinta es que lo muestre críticamente. Finalmente, es cierto, como dice O'Connor (1982: 787), que Leonor representa la situación expuesta de una mujer sin varones en la familia que la puedan proteger, pero no es cierto que Calderón pretenda denunciar la indefensión de Leonor: lo que muestra Calderón es que hasta el más humilde y desprotegido de los vasallos puede esperar socorro y protección de su rey. 
Calderón, supone apoyar un sistema de ofensas y reparaciones en el que la mera apariencia de delito implica la culpa y acarrea la venganza, algo absolutamente coherente con el desenlace de los hechos que nos presenta Calderón. La génesis de la obra desacredita al gracioso, no a Gutierre. El Rey apoya a Gutierre, y, en consecuencia, hace la vista gorda ante un asesinato vil e injusto.

Podrá objetarse también, es cierto, que el rey acude a la llamada de Coquín, y que si no salva la vida de Mencía es porque no puede. También es cierto que le produce cierto horror descubrir el cadáver desangrado de la mujer, y que hace un pequeño reproche a Gutierre por su precipitación, pero todos estos gestos, bastante insignificantes, pierden todo su significado cuando el rey decide, insisto, no sólo no castigar a Gutierre por el horrible crimen (véanse los versos 2923-2939: en este diálogo queda claro lo poco que le importa al rey el crimen), sino premiarlo y entregarle una nueva esposa (vv. 2940-2942) a la que Gutierre no duda en advertir que lo que ha hecho con Mencía lo repetiría sin dudarlo un instante con ella.

Calderón ejerce una profunda vocación anti-dialéctica sirviéndose de la categoría moral del honor, que actúa, además, y al contrario que en Lope, como elemento legitimador y justificante de las actuaciones criminales. El honor disuelve en la obra todo tipo de conflicto o dialéctica estamental de naturaleza socio-política. Pero en Calderón sí hay política y pone su obra al servicio de Ideas políticas muy determinadas: la reafirmación del Monarca. En este sentido, la tradición clásica sigue vigente en él.

El problema a la hora de juzgar como trágica la obra calderoniana, se deriva más bien de su tratamiento de la violencia. Acabar una obra tan terrible en claves cómicas, teniendo en cuenta, además, que el género trágico siempre nos ha ofrecido reflexiones valiosas sobre lo terrible de la violencia, por muy inevitable o necesaria que ésta sea, es algo con lo que ninguna tragedia puede casar. Un rey que, ante el cadáver de una mujer inocente, no castiga al culpable; una mujer a la que ni le espanta ni le admira el crimen; un hombre que recibe las nuevas nupcias amenazando a su futura esposa con la imagen del cuerpo inerte de la antigua... Y todo ello en medio de la alegría por una nueva boda... Injusticias que culminan en la muerte de una inocente sin que a nadie le importe, salvo al gracioso. La tragedia se diluye en Calderón a la vez que desaparece el respeto que se le debería a Mencía y mientras se constata la falta de dignidad de asesinos y espectadores, casi cómplices. Y no se trata de una crítica descontextualizada. Los griegos conocieron este respeto y esta dignidad, estaban presentes en su literatura, no se trata de ninguna extrapolación de sensibilidades modernas. Se trata del horror que, desde siempre, ha acompañado a la violencia y a la injusticia en toda tragedia que se precie. 


\section{BiBLIOGRAFÍA}

\section{1- FUENTES PRIMARIAS}

ARISTÓTELES 1974: Poética, edición trilingüe por Valentín García Yebra, Madrid: Gredos.

ARISTÓTELES 1994: Metafísica, introducción, traducción y notas de Tomás Calvo Martínez, Madrid: Gredos.

CALDERÓN DE LA BARCA 1633-1635/1989: El médico de su honra, edición de D. W. Cruickshank, Madrid: Castalia.

ESQUILO 2000: Tragedias, traducción y notas por B. Perea Morales, introducción por F. Rodríguez Adrados, Madrid: Gredos.

EURÍPIDES 1977: Tragedias, Vol. I, traducción y notas de A. Medina, J. A. López Férez; introducción general de C. García Gual, Madrid: Gredos.

EURÍPIDES 1985: Tragedias, Vol. II, introducciones, traducciones y notas de J. L. Calvo Martínez, Madrid: Gredos.

EURÍPIDES 1979: Tragedias, Vol. III, introducciones, traducciones y notas de C. García Gual y L. A. de Cuenca y Prado, Madrid: Gredos.

HOMERO 1997: Ilíada, edición y traducción de A. López Eire, Madrid: Cátedra.

LOPE DE VEGA 1631/1985: El perro del hortelano y El castigo sin venganza, editado por David Kossoff, Madrid: Castalia.

LOPE DE VEGA 2002: Novelas a Marcia Leonarda, edición de Antonio Carreño, Madrid: Cátedra.

PLATÓN 1992: Parménides; Teeteto; Sofista; Político en Diálogos V, introducción, traducción y notas de $\mathrm{M}^{\mathrm{a}}$. I. Santa Cruz, A. Vallejo Campos y N. L. Cordero, Madrid: Gredos.

PLATÓN 1998: República en Diálogos IV, introducción, traducción y notas por C. Eggers Lan, Madrid: Gredos.

ROJAS ZORRILA, F. de 1650/1996: Del rey abajo, ninguno, edición de Brigitte Wittmann, Madrid: Cátedra. Es la edición por la que citamos.

SÓFOCLES 1981: Tragedias, introducción por J. Lasso de la Vega, traducción y notas por A. Alamillo, Madrid: Gredos.

\section{2- FUENTES SECUNDARIAS}

ALVAR, M. 1987: «Reelaboración y creación en El castigo sin venganza», en R. Doménech (ed.), «El castigo sin venganza» y el teatro de Lope de Vega, Madrid: Cátedra (207-222).

BOARDMAN, J., GRIFFIN, J., MURRAY, O. (directores) 1986/1988: The Oxford History of the Cassical World, 2 vols., Oxford: Oxford University Press. Version española de Federico Zaragoza: Historia Oxford del Mundo clásico, Madrid: Alianza.

BUENO, G. 1996: El animal divino, Oviedo: Pentalfa.

CRAWFORD, J. P. W. 1922: Spanish drama before Lope de Vega, Philadelphia: Publicaciones de la Universidad de Pensylvania. 
DOMÉNECH, R. (ed.) 1987: «El castigo sin venganza» y el teatro de Lope de Vega, Madrid: Cátedra.

GARCÍA GUAL, C. 1988: «Democracia, tragedia y educación», conferencia y posterior coloquio, en Tragedia griega y Democracia, seminarios del XXXIV Festival de Teatro clásico de Mérida, Mérida: Editora regional de Extremadura (181-190).

GIL FERNÁNDEZ, L. 1988: «La democracia ateniense», conferencia y posterior coloquio, en Tragedia Griega y Democracia, seminarios del XXXIV Festival de Teatro Clásico de Mérida, Mérida: Editora regional de Extremadura (164-175).

JAEGER, W. (libros I y II: 1933, libro III: 1944, libro IV: 1945/2001), Paideia. Die Formung des Griechischen Menschen I-II, Berlin: Walter de Gruyter \& Co., 1936. Traducción española de J. Xirau (I-II) y W. Roces (III-IV), Méjico y España: F. C. E.

LESKY, A. 1937: Die griechische Tragödie, Stuttgart: Alfred Kröner Verlag, 1958. Trad. esp. de Juan Godó Costa, revisada por Montserrat Camps: La tragedia griega, Barcelona: El Acantilado, 2001.

MACCURDY, R. R. 1989: «Lope de Vega y la pretendida inhabilidad española para la tragedia. Resumen crítico», en A. Sánchez Romerazo (ed.), Lope de Vega: el teatro, vol. 1, Madrid: Taurus (163-190).

MACCURDY, R.R. 1979: «A Critical Review of El médico de su honra as Tragedy», Bulletin of Comediantes, 31 (3-14).

MORBY, E. S. 1943: «Some observations on Tragedia and Tragicomedia in Lope», Hispanic Review, 11 (185-209).

MURRAY, G. 1940/1954: Aeschylus: the Creator of Tragedy, Oxford, Carendon Press. Versión española de L. Mirlas: Esquilo: el creador de la tragedia, Madrid: Austral.

O’CONNOR, T. A. 1982: «El médico de su honra y la victimización de la mujer: la crítica social de Calderón de la Barca» en Asociación Internacional de Hispanistas, Actas VII, editado por G. Bellini, Roma, Bulzoni (783-789).

PARKER, R. 1997: «Gods cruel and kind tragic and civic theology», en C. Pelling (ed.), Greek tragedy and the historian, Oxford: Clarendon Press (143-160).

PEDRAZA, F. 2007: Sexo, poder y justicia en la comedia española, Vigo: Editorial Academia del Hispanismo.

PELLING, C. 1997: «Tragedy and ideology», en C. Pelling (ed.), Greek tragedy and the historian, Oxford: Clarendon Press (224-236).

RODRÍGUEZ ADRADOS, F. 1992: «El significado de La Orestíada dentro de la tragedia griega», en F. Rodríguez Adrados (ed.), La Orestíada (simposio de 1990), Madrid: Ediciones Clásicas (1-16).

SÁNCHEZ ROMERALO, A. (ed.) 1989: Lope de Vega: el teatro, 2 vols., Madrid: Taurus.

TRAPP, M. 1996: «Tragedy and the fragility of Moral reasoning: Responsey to Foley», en M. S. Silk (ed.), Greek tragedy and the tragic: Greek theatre and beyond, Oxford: Clarendon Press (73-84).

VARELA ÁLVAREZ, V. 2008: Destino y libertad en la tragedia griega, Vigo: Editorial Academia del Hispanismo.

VIDAL-NAQUET, P. 2001/2004: Le miror brisé. Tragédie athenienne et politique, 
Société d’Édition Ls Belles lettres. Traducción española de M. llenares García: El espejo roto: tragedia y política en Atenas en la Grecia antigua, Madrid: Abada Editores.

WARDROPPER, B. W. 1987: «Civilización y barbarie en El castigo sin venganza», en R. Doménech (ed.), «El castigo sin venganza» y el teatro de Lope de Vega, Madrid: Cátedra (191-206).

YNDURÁIN, D. 1987: «El castigo sin venganza como género literario», en R. Doménech (ed.), «El castigo sin venganza» y Lope de Vega, Madrid: Cátedra (141-162).

Violeta Varela Álvarez es Investigadora del Centro de Estudios Clásicos y humanísticos de la Universidad de Coimbra

Publicaciones recientes:

«El concepto de tragedia en la trilogía rural lorquiana», Revista Stichomythia, Revista de teatro contemporáneo de la Universidad de Valencia, 2009

Destino y libertad en la tragedia griega, Vigo (2008). ISBN 978-84-96915-29-9

Lineas de investigación:

Literatura trágica, con especial atención a la literatura hispánica y la antigüedad clásica, en relación con la Filosofía y la Política.

Dirección postal:

Calle Alcalde Luis Treillard, 23, 5 izq. Esc-3, 33405 Salinas (Asturias)

Correo electrónico: violetavarelaalvarez@yahoo.es 
